\title{
Discrimination between Alzheimer Dementia and Controls by Automated Analysis of Multicenter FDG PET
}

\author{
K. Herholz,* 1 E. Salmon, $†$ D. Perani, $†$ J-C. Baron, $\S$ V. Holthoff, $\|$ L. Frölich, $₫$ P. Schönknecht,** K. Ito, $\dagger \dagger$

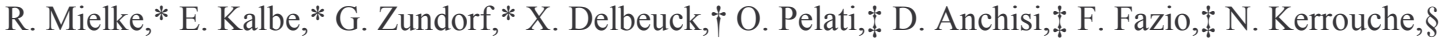

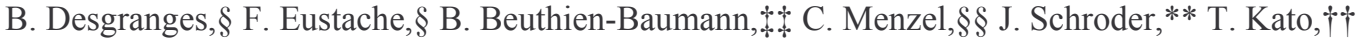 \\ Y. Arahata, $\dagger \dagger$ M. Henze, $|\|| \mid$ and W-D. Heiss*
}

*University Cologne, Neurological Clinic and Max-Planck-Institute for Neurological Research, 50931 Köln, Germany

$\uparrow$ Cyclotron Research Centre and Service of Neurology, University of Liège, Belgium;

$\$$ Institute of Neuroscience and Bioimaging-CNR, Institute H San Raffaele,University Vita-Salute HSR, University of Milano-Bicocca, Milan, Italy; §INSERM Unit 320, Cyceron, Caen, France; ||Department ofPsychiatry and Psychotherapy, University of Technology, Dresden, Germany; IDepartment of Psychiatry and Psychotherapy, University Frankfurt am Main, Germany;

** Section of Geriatric Psychiatry, University of Heidelberg, Germany;

$\uparrow$ National Institute of Longevity Sciences, Obu, Japan;

t+Department of Nuclear Medicine, University of Technology, Dresden, and PET-Center, Rossendorf Germany; $\S \S$ Department of Nuclear Medicine, University Frankfurt am Main, Germany; and ||| University of Heidelberg and German Cancer Research Center, Heidelberg, Germany

\begin{abstract}
A new diagnostic indicator of FDG PET scan abnormality, based on age-adjusted $t$ statistics and an automated voxel-based procedure, is presented and validated in a large data set comprising 110 normal controls and 395 patients with probable Alzheimer's disease (AD) that were studied in eight participating centers. The effect of differences in spatial resolution of PET scanners was minimized effectively by filtering and masking. In controls FDG uptake declined significantly with age in anterior cingulate and frontolat-eral perisylvian cortex. In patients with probable AD decline of FDG uptake in posterior cingulate, tem-poroparietal, and prefrontal association cortex was related to dementia severity. These effects were clearly distinct from age effects in controls, suggesting that the disease process of AD is not related to normal aging. Women with probable AD had significantly more frontal metabolic impairment than men. The new indicator of metabolic abnormality in ADrelated regions provided $93 \%$ sensitivity and specificity for distinction of mild to moderate probable AD from normals, and $84 \%$ sensitivity at $93 \%$ specificity for detection of very mild probable AD (defined by Mini Mental Score 24 or better). All regions related to AD severity were already affected in very mild AD, suggesting that all vulnerable areas are affected to a similar degree already at disease onset. Ventromedial frontal cortex was also abnormal. In conclusion, automated analysis of multicenter FDG PET is feasible, provides insights into AD pathophysiology, and can be used potentially as a sensitive biomarker for early AD diagnosis.
\end{abstract}

\section{INTRODUCTION}

The clinical diagnosis of Alzheimer's disease (AD) is defined by progressive memory impairment and other cognitive dysfunctions that are identified by medical and neuropsychological assessment. A major difficulty especially for large multicenter studies is the fact that neuropsychological instruments are often language dependent and culture specific, and single tests are mostly not comparable between different countries. Test results may also be influenced by the premorbid level of cognitive function. So far, no universal test battery for dementia is available except short screening tests, such as the Mini Mental Status Examination (MMSE) (Folstein et al., 1975), which must be complemented by additional tests for the diagnosis of dementia and has been criticized for a lack of sensitivity in early stages (Mungas et al., 1996; Grigoletto et al., 1999). Thus a biological indicator of $\mathrm{AD}$ that is not language and culture dependent continues to be of interest to facilitate objective diagnosis of $\mathrm{AD}$.

Many studies over the past two decades have demonstrated that AD is associated with regional reductions of the cerebral metabolic rate of glucose (CMR-Glc) mainly in precuneus, temporo-parietal, and frontal association cortex (see reviews by Rapoport, 1991; Herholz, 1995; Perani and Cappa, 2001). FDG PET is very sensitive to detect CMRGlc reductions very early in AD, including in subjects at high genetic risk but without clinical symptoms of dementia (Reiman et al., 1996; Small et al., 2000; de Leon et al., 2001). It is also more reliable for diagnostic purposes than single photon emission computed tomography (Mielke et al., 1994; Messa et al., 1994). The anatomical distribution of functional changes is closely related to impairment of some localized specific cognitive functions, such as aphasia, and their severity increases with progression of the disease (Haxby et al., 
1990). CMRGlc in cerebellum, striatum, primary visual, and sensorimotor cortex is relatively spared, and therefore the typical impairment of associative cortices can be identified without absolute quantitation of CMRGlc. Thus, noninvasive assessment of FDG distribution without blood sampling usually is sufficient, and FDG PET at a resting state is easy to acquire and well tolerated by patients. Scanners and image reconstruction algorithms including correction for scatter and attenuation are technically mature, and their availability has increased considerably in many countries in recent years due to their increasing clinical use for detection of malignant tumors. Yet, at present, brain PET scans are often interpreted in a qualitative manner only by visual reading, which heavily depends on observer experience and training and lacks a clearly defined cutoff to distinguish between normal and pathological findings. Thus, FDG PET seems to be well suited as a biological marker for $\mathrm{AD}$ if complemented by an objective image analysis procedure that can be widely and easily applied in different PET centers.

Most previous FDG PET studies were conducted within single laboratories. Yet, in a previous multi-center study Herholz et al. (1993) demonstrated that it is possible to pool data derived from standard regions of interest. In that study, normal controls and patients with probable AD of mild to moderate severity were discriminated with high accuracy. In a subsequent study, deterioration in patients with mild cognitive impairment was predicted by metabolic abnormalities (Herholz et al., 1999). With the progress of voxel-based methods for anatomical image normalization and statistical parametric mapping (Minoshima et al., 1995; Friston et al., 1995a; Signorini et al., 1999), completely automated techniques for image analysis can be developed and applied to large multicenter data sets. We collected the largest sample of FDG PET scans in normals and patients with probable AD that has been described as yet from eight centers in five countries with four different languages. We report the development of a completely user-independent analysis and its results.

\section{METHODS AND SUBJECTS}

The study comprises 110 normal controls (70 male, 40 female) and 395 patients (169 male, 226 female) with probable AD according to NINCDS-ADRDA criteria. Patients and controls were recruited at eight participating centers, who had performed clinical assessment, including neuropsychological testing and exclusion of other diseases by CT or MRI as required by NINCDS-ADRDA criteria, and PET scans in accordance with the study requirements. Neuropsychological testing batteries differed among centers, but it always included the Mini Mental Status Examination (Folstein et al., 1975) and, especially if MMSE was in the nondiagnostic range of 24 or higher, appropriate tests for immediate and delayed verbal memory, such as Buschke's selective reminding test (Grober et al., 1988) or the Wechsler memory scale (Wechsler, 1987), and verbal fluency were performed. In most patients testing was even more extensive including also specific tests for spatial memory, working memory, attention, language, and praxia and standard dementia rating scales (global deterioration scale (Reisberg etal., 1982), clinical dementia rating scale (Morris, 1993), or 2the Mattis dementia rating scale (Mattis, 1988; Fama et al., 1997)). Exclusion criteria were previous subarachnoid or intracerebral hemorrhage, intracranial tumors, hydrocephalus, all psychoses (including major depression), alcoholism, epilepsy, ischemic strokes, vascular dementia and other dementing illnesses, anemia, untreated thyroid dysfunction, renal insufficiency, and nonstabilized diabetes mellitus. Mean age of patients at the time of the PET study was $69 \pm 8$ years. Mean age at onset in patients was $66 \pm 9$ years (data not available in 64 patients), and mean MMSE score was $19 \pm 6$.

Healthy controls were recruited either by advertisement or as relatives of patients. They were interviewed to exclude dementia and all diseases that were exclusion criteria in the patient group. Most participating centers accepted treated medical conditions that are frequently present in clinically healthy controls such as arterial hypertension, hyperlipidemia, or compensated hypothyroidism. Controls who had subjective memory complaints were included if they had normal immediate and delayed memory tests, MMSE of 26 or higher, and no clinical evidence of dementia. Mean age of controls ( $57 \pm 13$ years) was lower than that in patients; therefore an agematched subset was selected for comparison with patients with probable AD.

Cases were acquired at eight centers, with PET scanners that differed with respect to field of view and spatial resolution (Table 1). Studies were done at a resting state with eyes closed and ears unplugged after intravenous injection of 110 to $370 \mathrm{MBq}$ 18F-2-fluoro-2-deoxy-D-glucose (FDG). Images of tracer distribution in brain were used for analysis that had been summed up from part of a dynamic series of scans at most participating centers. Required minimum time interval between injection and scan start was $30 \mathrm{~min}$. On average, scans were started 42 \pm 19 min after injection. Required minimum scan duration was $10 \mathrm{~min}$. On average, scan duration was $19 \pm 3$ min. Images were reconstructed using filtered backprojection including correction for attenuation (measured by transmission scan) and scatter using standard software as supplied by scanner manufacturers. 
TABLE 1: Overview on Participating Centers, Equipment, and Included Cases

\begin{tabular}{|c|c|c|c|c|c|c|}
\hline \multirow{2}{*}{$\begin{array}{l}\text { Participant } \\
\text { ID }\end{array}$} & \multirow{2}{*}{$\begin{array}{l}\text { Scanner type } \\
\text { (manufacturer) }\end{array}$} & \multicolumn{2}{|c|}{ Spatial resolution $(\mathrm{mm})$} & \multirow[b]{2}{*}{$\begin{array}{l}\text { Axial field of } \\
\text { view }(\mathrm{mm})\end{array}$} & \multicolumn{2}{|c|}{ Number of cases } \\
\hline & & In-plane FWHM & Slice thickness & & Controls & $\mathrm{AD}$ \\
\hline 1 & ECAT EXACT (1) & 6 & 3.375 & 162 & 15 & 51 \\
\hline & ECAT EXACT HR (1) & 3.6 & 3.125 & 150 & 18 & 72 \\
\hline 2 & ADVANCE (2) & 4.6 & 5.3 & 154 & 10 & 18 \\
\hline 3 & ECAT 951 (1) & 8.5 & 3.37 & 108 & 25 & 188 \\
\hline 4 & ECAT EXACT HR+ (1) & 3.6 & 2.46 & 155 & 12 & 27 \\
\hline 6 & ECAT EXACT HR+ (1) & 3.6 & 2.46 & 155 & 7 & 21 \\
\hline 7 & ECAT EXACT 47 (1) & 6.7 & 3.3 & 164 & 5 & 10 \\
\hline 8 & ECAT EXACT HR+ (1) & 3.6 & 2.46 & 155 & 0 & 13 \\
\hline 10 & ECAT EXACT HR (1) & 3.6 & 3.125 & 150 & 13 & 0 \\
\hline
\end{tabular}

Note. Manufacturers: (1) Siemens/CTI, (2) General Electric.

Basic image processing was done by MATLAB, using SPM99 routines (Wellcome Department of Cognitive Neurology, London, UK) for spatial normalization. Further image analysis was performed using newly developed IDL (Research Systems Incorporated, Boulder, CO) programs. MPITool (Pietrzyk etal, 1996) was used for image display. SAS (SAS Institute, Inc., Cary, NC) was used for statistical evaluation of results.

All data were spatially normalized by affine 12-parameter transformation (Friston et al. 1995a) using the SPM99 standard PET brain template. Normalized images were represented on a 79 X 95 X 68 matrix with 2 X 2 X 2 $\mathrm{mm}$ voxel size. Images were then smoothed by a Gaussian filter of $12 \mathrm{~mm}$ FWHM that was limited to measured brain tissue using the IDL fast Fourier transform routine. To achieve that, the same filter was applied to a binary brain mask (with values 1 for measured voxels, 0 for nonmeasured voxels). The filtered image voxels were divided by the filtered binary mask values to compensate for signal loss due to the contribution of nonmeasured voxels (with zero signal). Thus, signal distortion due to filtering at the edges of measured data was avoided.

Special precautions were taken to minimize effects caused by differences of scanner resolution on the results. Smoothed normal scans obtained from high-resolution scanners (with axial resolution better than $6.0 \mathrm{~mm}$ ) were compared to those from low-resolution scanners. A gray matter mask was defined by those voxels that had an intensity above whole-brain average on both scanner types. The mask contained 144,823 voxels (1159 ml). It did not include voxels from the uppermost 10 slices (i.e., from the top $20 \mathrm{~mm}$ of the brain) because confounding effects of spatial resolution were most prominent in these parts of the cortex. All images were scaled to an average intensity of 1 within this mask. In some instances there were scans that did not fill the entire mask due to unfortunate positioning of the head in the scanner. On average, $99.3 \%$ of the mask volume was within the fieldof-view, with a minimum of $90.4 \%$ in one instance. Nonmeasured voxels were excluded from analysis, and statistical calculations were adjusted to a reduced number of subjects in voxels that were not present in all data sets. Intensity scaling of all images was also done after exclusion of nonmea-sured voxels.

The influence of age and dementia severity (MMSE) was studied by regression analysis. The regression line and the standard error of the regression slope were determined. Student $t$ values were calculated to test the significance of the regression (Steel and Torrie, 1980). Comparisons of FDG uptake between subject groups were also done on $t$ maps. Local critical $t$ values were calculated for a significance level of $P=0.05$ (one-sided) with Bonferroni correction for multiple testing on 670 resolution elements (containing 216 voxels, as defined by the filter volume) within the mask. Only spatially contiguous clusters containing the volume of at least one resolution element (216 voxels) above that threshold were regarded as significant.

With the view of developing a potential diagnostic test we first established the normal range of FDG uptake in individual voxels. For that purpose, a random reference sample of 49 subjects was drawn from the whole sample of control subjects. Age regression was performed and the variance of predicted values was calculated for each voxel. Abnormal voxels were defined in individual images as those voxels whose values were lower than $95 \%$ age-adjusted prediction limits (Steel and Torrie, 1980), and corresponding $t$ maps with reference to the values expected by the regression were calculated.

The next step was the development of an indicator whether an individual brain scan was normal or abnormal. 
This was necessary because even in normal scans approx. 5\% of voxels (i.e., 7241 of 144,823) could be expected to show "abnormal" values lower than the $95 \%$ age-adjusted prediction limit. The sum of $t$ values over all voxels with FDG uptake below the $95 \%$ age-adjusted prediction limit was selected as a global indicator of scan abnormality ( $t$ sum). To focus the search for abnormal voxels to those areas that are typical for Alzheimer's disease, a mask was defined by all voxels that had shown a close correlation (at $P<0.01$ uncorrected) with MMSE in patients with probable AD (see Fig. 1). The sum over all $t$ values of voxels with FDG uptake below the $95 \%$ age-adjusted prediction limit within this AD mask (AD $t$ sum) was calculated for each individual.

In a third step, the normal range of these two indicators of scan abnormality, $t$ sum and AD $t$ sum, was studied. This was done in an independent sample comprising the remaining 61 normal subjects in order to avoid any bias that could have resulted from applying a criterion of abnormality to the same sample from which it had been derived from. Thus, the distribution of $t$ sum and AD $t$ sum was determined in subjects of the normal sample, who had not been used in the definition of abnormal voxels. Normal distribution was achieved by square-root transformation of $t$ sum and $\mathrm{AD} t$ sum values prior to calculation of statistical tests.

Diagnostic accuracy for AD was determined by receiver operating characteristic (ROC) analysis (Metz, 1978). The indicators of scan abnormality, $t$ sum and $\mathrm{AD} t$ sum, were tested for their ability to discriminate between patients with probable $\mathrm{AD}$ and 28 age-matched controls, again including only controls from the second sample that had not been used for definition of abnormal FDG uptake.

\section{RESULTS}

\section{Normal Controls}

Average voxel values reflected the well-known distribution of CMRGlc. Local standard deviation showed some regional variations with an average of 0.09 across the whole masked brain, and values in the range 0.06 to 0.10 in most parts of cortex. Higher standard deviations up to a maximum of 0.26 were found in those parts of the basal ganglia that are adjacent to the ventricles, probably reflecting the high contrast and the spatial variability due to varying degrees of atrophy at the CSF- brain border that was not eliminated by spatial normalization. Standard deviation was also high with values of 0.15 to 0.20 at the occipital pole, the gray/white matter interface in frontal and parietal lobes, the middle part of cingulate gyrus, and in orbito-frontal cortex. These areas are known to show more variability of individual gyration that cannot completely be accounted for by affine spatial normalization than the other parts of the brain (Thompson et al., 1996, 1998).

There was a significant effect of age on local FDG uptake (Fig. 2). A significant decline with age was found in most parts of frontal cortex, most strongly in the anterior cingulate and in frontolateral perisylvian cortex bilaterally (Table 2a). A pronounced decline was also present in those parts of the basal ganglia that are adjacent to the ventricles, which are subject to incomplete recovery of activity because of atrophy effects (Mazziotta et al., 1981) and had shown the high standard deviation in the analysis of average uptake. A relative increase with age, reflecting preservation of CMRGlc, was present in most parts of occipital, temporal, and sensorimotor cortex which was strongest in primary visual cortex.

\section{Patients with Probable AD}

Average FDG uptake in patients with probable AD demonstrated the typical distribution with temporoparietal and frontal reductions. Local standard deviation with an average of 0.14 across the masked brain was generally larger than that in controls, probably due to changes of FDG uptake caused by the disease.

The effect of dementia severity on FDG uptake (Fig. 2) was largest in an extended region that included temporoparietal cortex, posterior cingulate, and precuneus, and in frontal association cortex bilaterally (Table $2 b)$. Some decline of FDG uptake was also noted in those parts of the basal ganglia that are adjacent to the ventricles, similar to the effect of age and probably related to atrophy. There was very little overlap between the brain regions with dementia-associated metabolic impairment and those with age-related metabolic decline in normals (red areas in Fig. 2: 392 voxels, representing 2\% of all dementia-associated voxels).

Relative preservation of FDG uptake in dementia, resulting in a relative increase with MMSE, was observed in midbrain, putamen, insula, and sensorimotor and visual cortex (Table 2c). Previous studies that evaluated CMRGlc in absolute units had shown that there is no actual increase of CMRGlc in those regions but only relative preservation of CMRGlc (Herholz et al., 1990). Thus, we used those regions (defined by $P<0.01$, uncorrected) as a new reference to scale scans, instead of the global average, for the analyses described below.

A significant decline of FDG uptake in all brain regions that are typically affected in AD was already present in patients with probable AD with a MMSE score of 24 or higher (Figs. 3 and 4). A significant reduction of FDG uptake was also noted in a small region in ventromedial frontal cortex (Table 2d). At more severe stages of the dementia (i.e., MMSE <24), impairment in these areas became significantly more severe, but the spatial distribution of changes remained essentially unchanged. 
FIG. 1. Normal brain FDG uptake in shown in a gray scale within the mask used for data analysis. Regions that show decline of FDG uptake correlated with dementia severity in patients with probable AD are marked by red overlay; regions that have relatively preserved FDG uptake in AD are marked by blue overlay. Slices are 2 mm thick and parallel to the AC-PC level which is marked by a box.

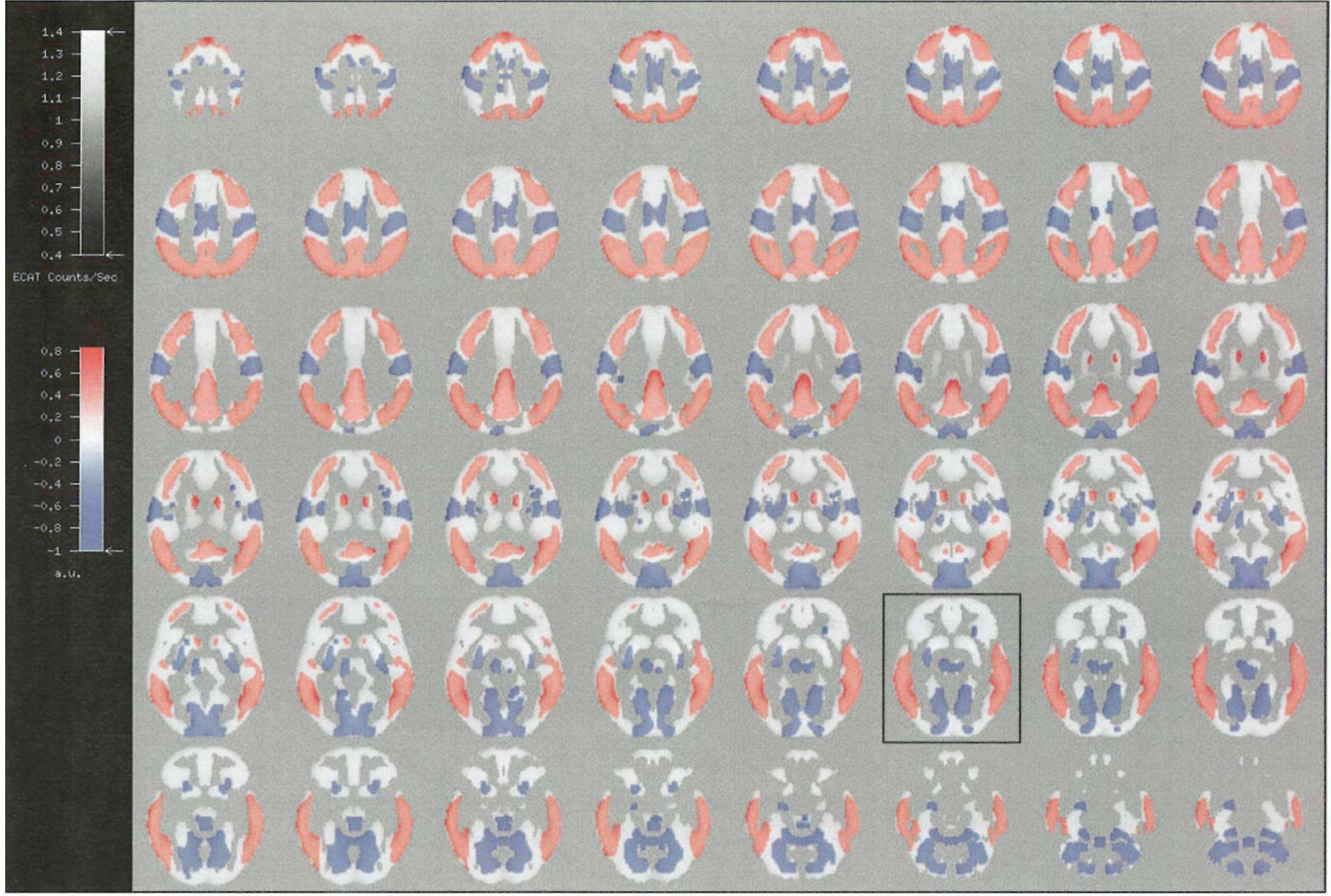


FIG. 2. Gray matter mask (blue), regions with significant decline of FDG uptake related to age in controls (green), regions with significant decline of FDG uptake related to dementia severity (orange), and overlap of these effects (red).

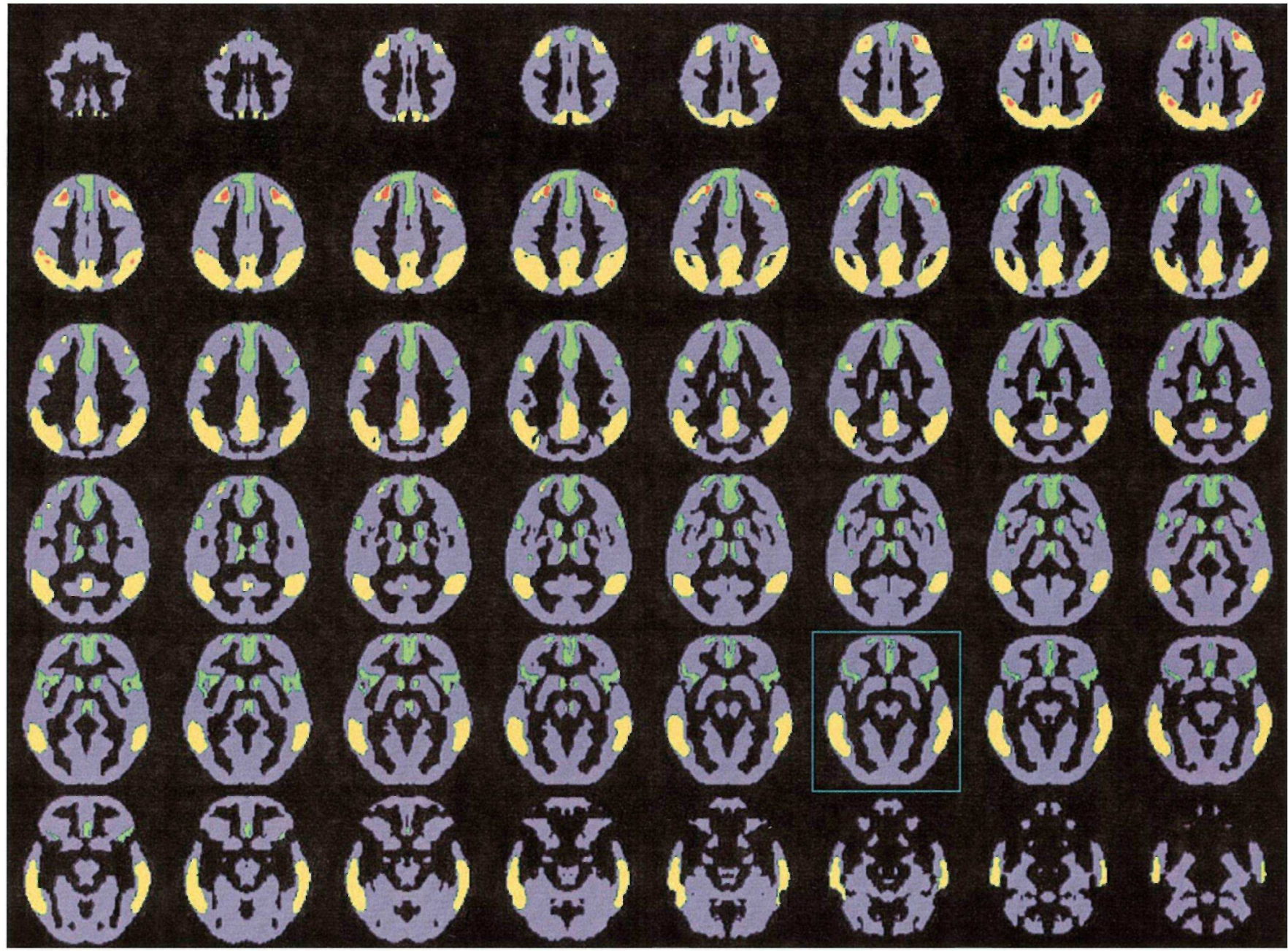


Published in: Neuroimage (2002), vol. 17, iss. 1, pp. 302-316

Status: Postprint (Author's version)

TABLE 2: Location of Significant Voxel Clusters (Thresholded at $P<0.05$ with Correction for Multiple Comparisons)

\begin{tabular}{|c|c|c|c|c|c|}
\hline \multicolumn{6}{|c|}{ Stereotactic coord of maximum } \\
\hline $\begin{array}{c}\text { Size } \\
\text { (voxels) }\end{array}$ & Maximum t & $\mathrm{x}$ & & & Anatomical structures \\
\hline \multicolumn{6}{|c|}{ (a) Age-related decline of FDG uptake in controls } \\
\hline 6998 & 10.0198 & -2 & 26 & 36 & Medial and superior frontal gyrus, right and left \\
\hline 1231 & 8.52082 & -40 & 18 & 2 & Left inferior frontal gyrus \\
\hline 1146 & 8.41626 & -8 & 6 & 18 & Left head of caudate/ventricle interface \\
\hline 1448 & 8.18099 & 44 & 18 & -4 & Right inferior frontal gyrus \\
\hline 294 & 7.02169 & 12 & 6 & 18 & Right head of caudate/ventricle interface \\
\hline 313 & 5.68729 & 28 & 28 & 60 & Right superior frontal gyrus \\
\hline \multicolumn{6}{|c|}{ (b) MMSE-related decline of FDG uptake in patients with probable AD } \\
\hline 18623 & 9.65401 & -64 & -42 & -6 & $\begin{array}{l}\text { Left and right temporoparietal association cortex, } \\
\text { posterior cingulate and precuneus }\end{array}$ \\
\hline 1151 & 6.24284 & -30 & 16 & 66 & Left superior frontal gyrus \\
\hline 850 & 5.94052 & 38 & 18 & 62 & Right superior frontal gyrus \\
\hline \multicolumn{6}{|c|}{ (c) Preserved FDG uptake in patients with probable AD (relative increase related to MMSE) } \\
\hline 3560 & 9.85866 & 38 & -4 & 16 & Right putamen, midbrain, insula, and motor cortex \\
\hline 5313 & 9.70108 & -22 & -22 & 18 & Left putamen, midbrain, insula, and motor cortex \\
\hline 11156 & 9.07434 & 8 & -60 & -8 & Left and right visual cortex and cerebellum \\
\hline 2088 & 8.60933 & -10 & -8 & 68 & Left and right superior medial frontal gyrus \\
\hline \multicolumn{6}{|c|}{ (d) Reduced FDG uptake in patients with very mild AD (MMSE 24 or higher) compared to normal controls } \\
\hline 22554 & 9.58125 & -4 & -58 & 32 & $\begin{array}{l}\text { Right and left post. cingulate, precuneus and left } \\
\text { temporoparietal and frontal association cortex }\end{array}$ \\
\hline 6812 & 7.39844 & 52 & -62 & 52 & Right temporoparietal association cortex \\
\hline 1985 & 6.20894 & 48 & 16 & 36 & Right frontal association cortex \\
\hline 316 & 4.97733 & -2 & 32 & -10 & Right and left ventromedial frontal cortex \\
\hline
\end{tabular}

Discrimination between Controls and Patients with Probable 
First, possible confounding effects of age and scanner resolution were studied in controls. In whole brain $t$ sum tended to be higher in high-resolution scanners than in low-resolution scanners (Table 3a), but differences were not significant and there was no effect of age. When analysis was limited to those regions that had shown a significant relation with dementia severity (AD $t$ sum, Table $3 \mathrm{~b}$ ), these values tended to be higher in younger controls, but again differences were not significant, and there was no effect of scanner resolution. Mean control values were 15,419.6 \pm 9096.4 for $t$ sum as a global measure of abnormality, and 4673.0 \pm 3187.25 for AD $t$ sum as a measure of abnormality in AD-related regions.

Patients with probable AD had much higher $t$ sum and AD $t$ sum scores than normals (Table 4). There were no differences with respect to scanner resolution, but patients with early-onset dementia (age at onset $<65$ years) had significantly higher $t$ sum and AD $t$ sum scores $(P<0.0001)$, even after adjustment for the slightly more severe dementia in the early-onset group (MMSE scores $16.6 \pm 6.2 \mathrm{vs} 18.2 \pm 5.4, P=0.04$ ). The $t$-score sums were significantly related to dementia severity $(r=0.56, P<0.0001$ for $t$ sum, and $r=0.61, P<0.0001$ for AD tsum, Fig. 5). There was no significant effect of gender on $t$-score sums, although values tended to be slightly lower in women.

$\mathrm{AD} t$ sum provided the best discrimination between patients with probable AD and age-matched controls. The area under the ROC curve (AUC) was 0.97 (Fig. 6). At an AD $t$ sum threshold of 10,150 sensitivity was $93 \%$ at a specificity of $93 \%$. This threshold was very similar to the $95 \%$ confidence limit of AD $t$-sum distribution in normal controls at 10,953. AD tsums generally corresponded well with visual appearance of the scans. As illustrated in Fig. 7, scans with AD tsums of 10,000 or less clearly appeared normal, and those with AD $t$ sums of 20,000 or higher clearly appeared abnormal, whereas in the range between 10,000 and 20,000 visual appearance would have been open for subjective interpretation. The two controls misclassified as AD by AD $t$ sum had values of 10,768 and 11,240 just above the critical threshold with very mild abnormalities in temporoparietal cortex. In all patients with probable AD but normal AD $t$ sums visual examination of scans also did not reveal abnormalities that would have been judged as typical for AD. In four cases focal metabolic reductions of unknown clinical significance were present: left thalamus and frontal cortex, frontal cortex (associated with severe general atrophy), left parahippocampal gyrus, and left hippocampus and frontal cortex.

In patients with very mild dementia (MMSE 24 or higher) sensitivity was still $84 \%$ (at the same specificity, AUC 0.93). Even when only patients with MMSE of 27 or higher (average MMSE 27.8 \pm 0.7 , age $65.5 \pm 6.6, n=17$ ) were selected and matched to normal controls in whom MMSE scores had been recorded (average MMSE 28.1 \pm 1.1 , age $64.5 \pm 8.0, n=17$ ), probable $\mathrm{AD}$ patients were identified with $83 \%$ sensitivity and $82 \%$ specificity (AUC 0.89). In senile patients and controls (age 65 or higher) discrimination was maintained at a high level ( $93 \%$ sensitivity at $90 \%$ specificity, AUC 0.97 ), in spite of the somewhat lower average AD $t$-sum scores in lateonset dementia. Discrimination by $t$-sum values over all abnormal voxels was generally less accurate with a sensitivity of $87 \%$ (AUC 0.95 ) in the whole patient group and $72 \%$ (AUC 0.90 ) in very mild dementia. 
FIG. 3. Difference ( $t$ map) between age-matched controls and very mild AD with MMSE scores of 24 or higher. The brightest areas mark the extent of significant changes with cross hairs at the local extreme values (see Table 2d).

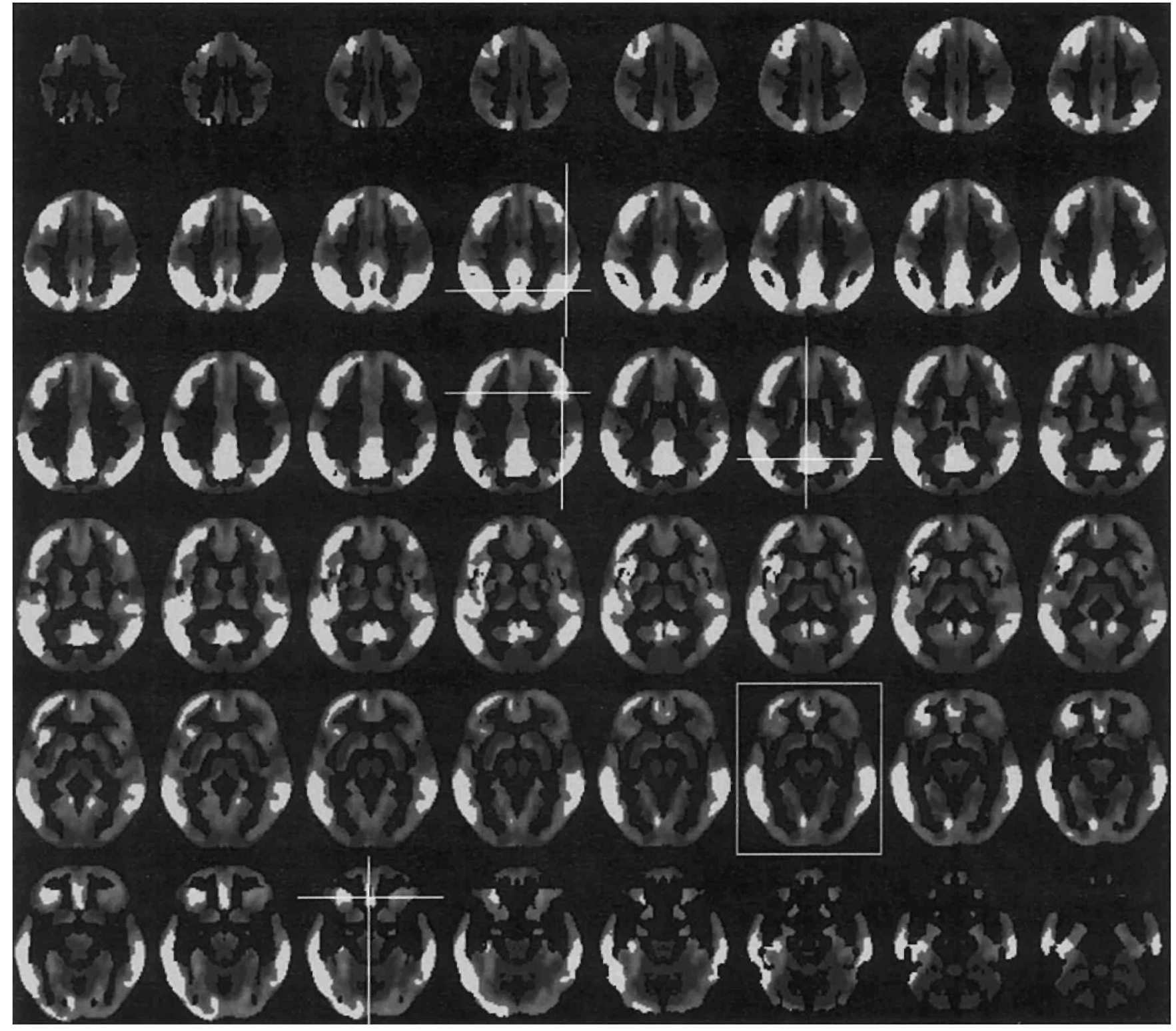


FIG. 4. $t$ map of a patient with very mild AD (MMSE 27, age 75 years). Significant voxels $(P<0.05$, uncorrected) are marked white, and maxima of connected clusters are marked by cross hairs. $t$-sum (26953.5) was within normal limits, but AD $t$ sum (17369.6) clearly exceeded the age-adjusted 95\% prediction limit of 11089.8

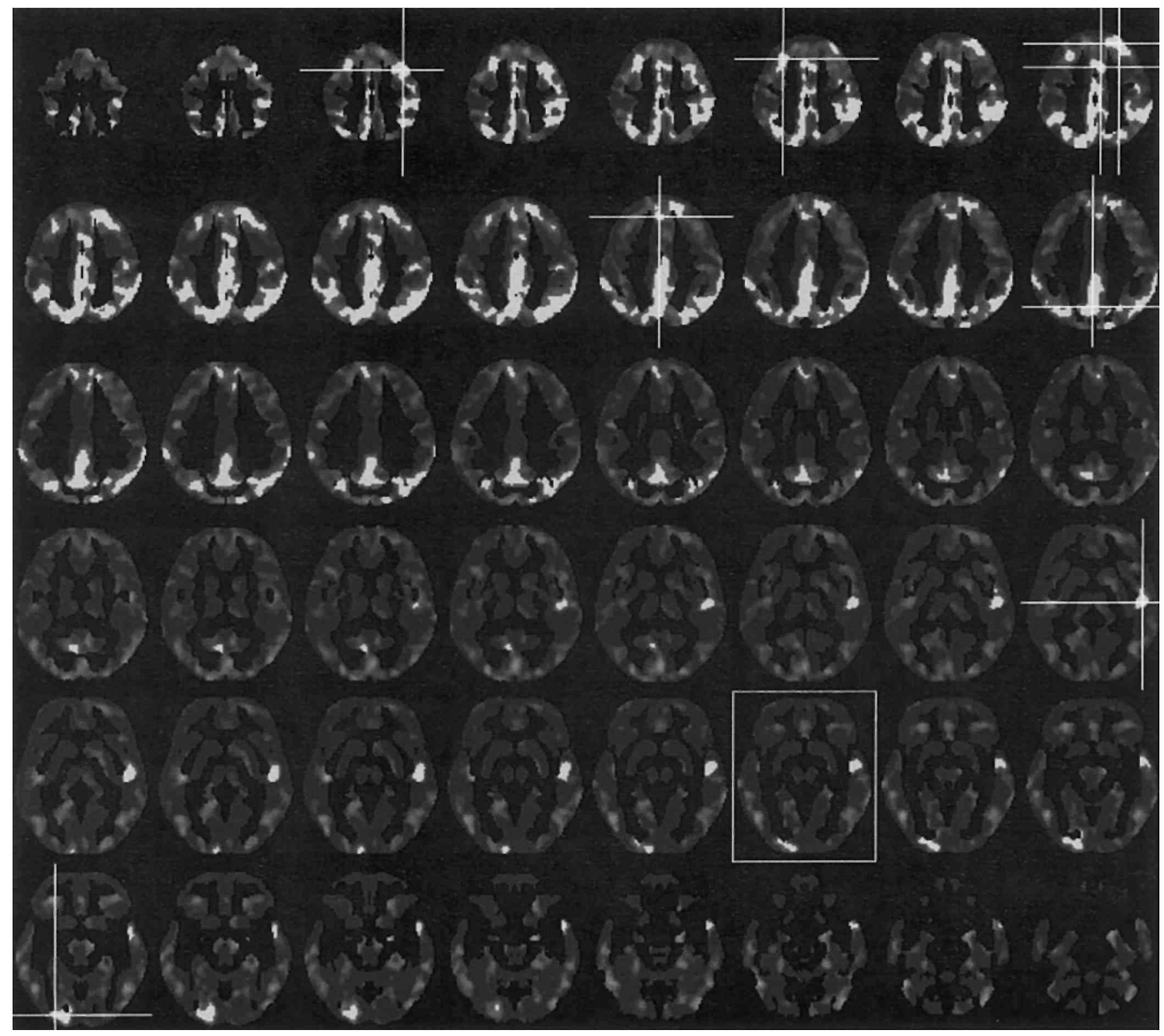

\section{Anatomical Distribution of Abnormalities in AD}

We also checked the relative contribution of frontal, temporo-parietal, and posterior cingulate areas to the total AD tsum in patients (Table 5). More than $50 \%$ of metabolic reductions were located in temporoparietal regions. Women had significantly more frontal impairment $(0.29 \pm 0.11)$ than men $(0.27 \pm 0.12, P=0.02$ in $t$ test $)$, whereas men had more temporo-parietal impairment $(0.55 \pm 0.10)$ than women $(0.52 \pm 0.10, P=0.01)$. There was no significant relation of the regional distribution with dementia severity or age at onset. Yet, metabolic impairment was significantly more severe in left hemispheric regions (asymmetry index $(l-r) /(l+r)$ was 0.03 $\pm 0.11, P<0.001$ in $t$ test). Regression of the asymmetry index on MMSE showed a tendency for more prominent left impairment in mild AD, but neither intercept nor slope was significant.

\section{DISCUSSION}

In the present study we developed and validated a new quantitative parameter, the sum over all $t$ values of abnormal voxels in the AD mask (AD tsum), which provides a measure of the depth and extent of metabolic abnormality in brain regions that are typically affected in AD. It represents the severity of functional impairment of the association cortices, is significantly related to dementia severity, and discriminates between normals and 
patients with high accuracy. The approach combines the virtues of voxel-based parametric mapping with the diagnostic information that can be drawn from the topographic distribution of abnormal findings. It is an alternative to the use of ratios (Herholz et al., 1990; Minoshima et al., 1995) or mul-tivariate procedures (Kippenhan et al., 1992; Ichimiya et al., 1994; Rapoport, 1997).

TABLE 3: Abnormal Voxel Indices in Controls by Age and Scanner Resolution

Resolution

Age $t$ sum $\quad$ High $\quad$ Low

(a) Sum of $t$ scores across all abnormal voxels ( $t$ sum)

$\begin{array}{lllll}\leq 60 & N & 20.00 & 13.00 & 33.00 \\ & \text { Mean } & 16425.07 & 13941.30 & 15446.61 \\ & \text { Std } & 7910.01 & 7474.12 & 7721.22 \\ >60 & N & 13.00 & 15.00 & 28.00 \\ & \text { Mean } & 17676.74 & 13404.00 & 15387.77 \\ & \text { Std } & 9411.00 & 11547.76 & 10640.34 \\ \text { All } & N & 33.00 & 28.00 & 61.00 \\ & \text { Mean } & 16918.15 & 13653.46 & 15419.60 \\ & \text { Std } & 8411.20 & 9697.79 & 9096.39\end{array}$

(b) Sum of $t$ scores in AD-related regions (AD $t$ sum)

\begin{tabular}{lllll}
$\leq 60$ & $N$ & 20.00 & 13.00 & 33.00 \\
& Mean & 5232.02 & 4861.50 & 5086.06 \\
& Std & 3057.53 & 3031.95 & 3005.29 \\
$>60$ & $N$ & 13.00 & 15.00 & 28.00 \\
& Mean & 4249.07 & 4131.73 & 4186.21 \\
& Std & 2824.15 & 3895.31 & 3378.77 \\
All & $N$ & 33.00 & 28.00 & 61.00 \\
& Mean & 4844.80 & 4470.55 & 4673.01 \\
& Std & 2963.02 & 3477.17 & 3187.25 \\
\hline
\end{tabular}


TABLE 4 : Abnormal Voxel Indices in Patients by Age at Onset and Scanner Resolution Resolution

Age $t$ sum $\quad$ High All

(a) Sum of $t$ scores across all abnormal voxels ( $t$ sum)

$\begin{array}{lllll}<65 & N & 61.00 & 72.00 & 133.00 \\ & \text { Mean } & 128119.43 & 120591.43 & 124044.12 \\ & \text { Std } & 78711.54 & 71970.87 & 74942.81 \\ \geq 65 & N & 60.00 & 138.00 & 198.00 \\ & \text { Mean } & 87242.96 & 73323.10 & 77541.24 \\ & \text { Std } & 46627.43 & 45392.72 & 46099.87 \\ \text { NA } & N & 30.00 & 34.00 & 64.00 \\ & \text { Mean } & 85734.68 & 91447.20 & 88769.46 \\ & \text { Std } & 77441.56 & 51056.93 & 64298.84 \\ \text { All } & N & 151.00 & 244.00 & 395.00 \\ & \text { Mean } & 103456.31 & 89796.62 & 95018.43 \\ & \text { Std } & 70058.09 & 58860.96 & 63636.13\end{array}$

(b) Sum of t-scores in AD-related regions (AD-t-sum)

\begin{tabular}{lllll}
$<65$ & $N$ & 61.00 & 72.00 & 133.00 \\
& Mean & 78868.44 & 74842.09 & 76688.76 \\
& Std & 50156.91 & 45029.81 & 47309.73 \\
& $N$ & 60.00 & 138.00 & 198.00 \\
& Mean & 46912.29 & 41945.94 & 43450.89 \\
& Std & 28296.76 & 29653.26 & 29266.79 \\
& $N$ & 30.00 & 34.00 & 64.00 \\
& Mean & 40427.72 & 51813.90 & 46476.63 \\
& Std & 40746.98 & 34028.66 & 37464.85 \\
All & $N$ & 151.00 & 244.00 & 395.00 \\
& Mean & 58533.40 & 53028.04 & 55132.62 \\
& Std & 43931.43 & 38162.74 & 40499.00 \\
\hline
\end{tabular}

The present study confirms the high sensitivity of FDG PET to detect AD that has also been found in previous studies by visual rating (Salmon et al., 1994), by a metabolic ratio based on regions of interest (Her-holz et al., 1993), and by stereotactic surface projection analysis (Minoshima et al., 1995). In these studies, clinical diagnosis of probable AD was used as a standard which may not be accurate in all cases. Although low accuracy was reported in community-based case series (Mendez et al., 1992; Lim et al., 1999), reasonable accuracy in the range 87 to $100 \%$ is usually achieved when clinical diagnosis is established according to standard criteria in academic hospitals (Morris et al., 1988). High sensitivity (93\%) of FDG PET was also confirmed in a series of 138 patients with pathological confirmation of AD (Silverman et al., 2001). High sensitivity for very early AD is evident from studies of asymptomatic subjects at high genetic risk for AD, which showed FDG PET abnormalities in areas typical for AD (Reiman et al., 1996; Small et al., 2000; de Leon et al., 2001).

Specificity is a more complex issue. With respect to the distinction from normal controls, values in the same range as for sensitivity (90\% or higher) were usually found (Herholz et al., 1993; Minoshima et al., 1995) in accordance with the present series. Yet, with the present data we cannot determine the specificity for distinction of $\mathrm{AD}$ from other types of dementia. The autopsy data that are available so far suggest that it may be in the range 63 to 78\% (Hoffman et al., 2000; Silverman et al., 2001). Thus, in patients presenting with cognitive symptoms, regional brain metabolism is sensitive to the presence of $\mathrm{AD}$, and to neurodegenera-tive disease generally. A negative PET scan helps provide assurance that cognitive abilities are likely to remain stable in the next 2 years following the study (Herholz et al., 1999). 
FIG. 5. Regression of $t$ score sum in AD-related areas vs dementia severity. Solid circles denote early-onset, open circles late-onset $\mathrm{AD}$, and diamonds patients in whom age at onset was not available. The range of values found in age-matched controls is shaded.

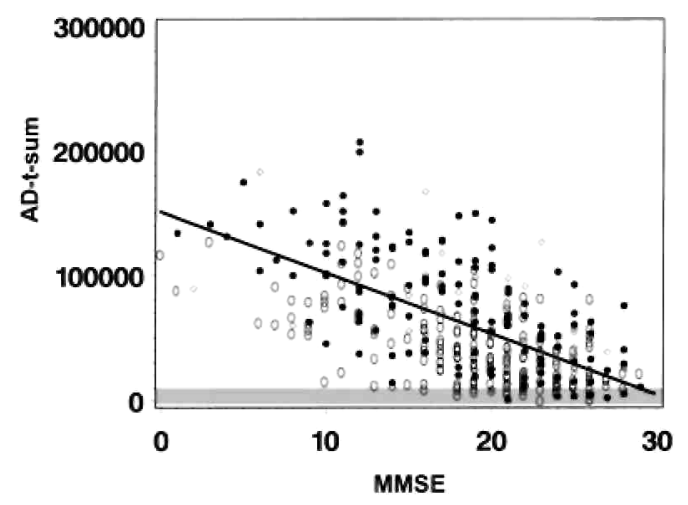

FIG. 6. ROC curve for diagnostic discrimination between age-matched controls (not including controls in whom normal range was determined) and patients with probable AD. The dashed curve represents the analysis in very mild AD (MMSE $\geq 24)$.

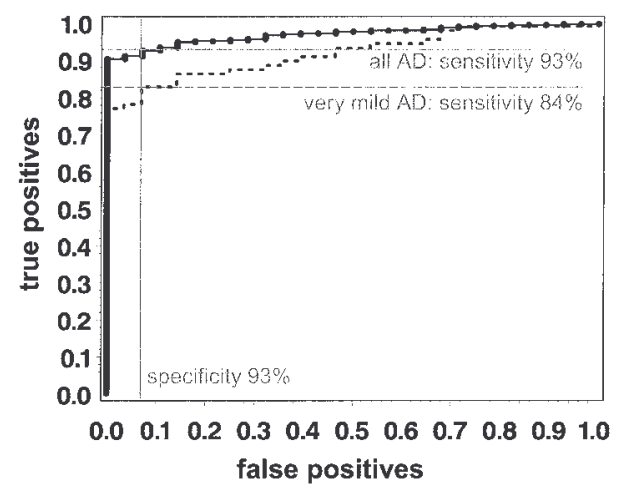


FIG. 7. Comparison of spatially normalized FDG uptake (top of each triplet, gray scale of full intensity range with $20 \%$ background subtraction, transaxial slice $42 \mathrm{~mm}$ above AC-PC plane), corresponding deviation from normal reference sample (maximum intensity voxels represent significant reduction at $P<0.05$, uncorrected), and associated $t$-sum scores (values rounded) in a representative sample of 12 individual scans from the study. Scans within the box (right bottom) are from normal individuals; all others are from patients with probable AD.
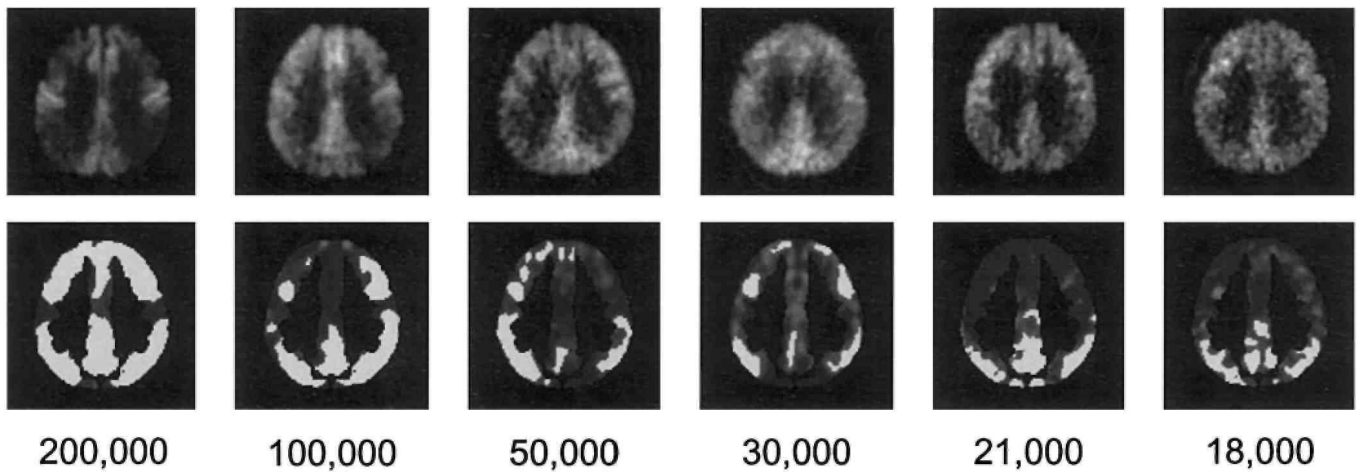

100,000
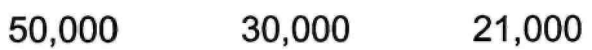

18,000
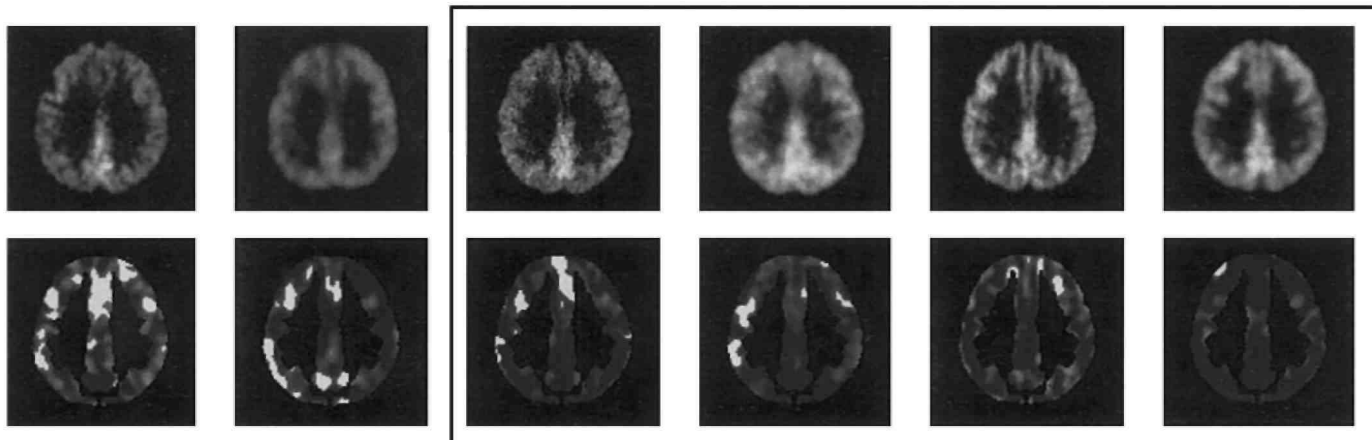

15,000

12,000

9,000

6,000

3,000

500

TABLE 5: Proportion of Abnormal $t$ values within AD-Typical Regions

Mean Std

\begin{tabular}{lll}
\hline Left frontal & 0.15 & 0.07 \\
Right frontal & 0.13 & 0.06 \\
Left temp. -par. & 0.28 & 0.08 \\
Right temp. -par. & 0.25 & 0.09 \\
Precuneus & 0.19 & 0.07 \\
\hline
\end{tabular}

The consistency of the present study with previous findings suggests that the results of the present method are well comparable to other methods, such as visual scan interpretation by experienced observers (see also Fig. 7), ROI-based analysis (Herholz et al., 1990), and standardized surface projections (Minoshima et al., 1995). Yet, the present study demonstrates for the first time use of a completely automated method in a large multicenter study.

Metabolic reduction in ventromedial frontal cortex has not been noted previously with PET and its detection in this study is probably due to the statistical power provided by the large sample size. It may correspond to neurofibrillary tangles and Alz 50 immunore-active neurons that have been found in this area (Chu et al., 1997). Otherwise, location of reduced FDG uptake in AD in this study was very similar to that found in previous studies (see Herholz, 1995, for a review of ROI data, and Minoshima et al., 1995, and Signorini et al., 1999, for voxel data). Yet, we could not confirm a preferential affection of the posterior cingulate and precuneus in early AD, but found that the relative proportion of abnormalities in posterior cingulate, tem-poro-parietal, and fronto-lateral association cortex was independent from disease severity, suggesting that, in a patient population, all of these vulnerable areas are affected right from the outset. Across patients, the metabolic impairment seems to be more narrowly and consistently localized in the precuneus and posterior cingulate than in the more extended frontal and tem-poroparietal association cortex, which could be the reason that maximum reduction in early AD is found 
there by parametric mapping (see Table $2 \mathrm{~d}$ and Minoshima et al., 1995). The more widespread temporo-lateral and frontal impairment was demonstrated with SPM in smaller AD samples (Desgranges et al., 1998; Salmon et al., 2000) less consistently because it affects only the same region but not necessarily the same voxels in different patients.

Impairment of frontolateral association cortex was stronger in women than in men. To our knowledge, this finding has not been reported before with PET and its detection may also be due to the higher power of our large sample. It is currently unclear whether it is related to inferior performance of women with AD in naming and verbal fluency tasks and in delayed recall that has been noted in a large neuropsychological study (Henderson and Buckwalter, 1994), and further detailed comparisons between FDG PET and neuro-psychological testing are required.

Similar to previous studies (Loewenstein et al., 1989), we found more severe abnormalities in the left than in the right hemisphere. This asymmetry tended to be more prominent in mild dementia. We therefore assume that it may be due to a selection bias caused by the fact that left hemispheric impairment is often related to aphasic disturbance (Haxby et al., 1985), which may more frequently lead to referral for PET studies than the visuospatial deficits that are related to right hemispheric impairment and may more easily be tolerated in mild dementia.

The comparison of the locations of dementia-associated metabolic impairment and age-related decline in normals showed that they are quite distinct. This suggests that AD is a disease process that is not related to normal aging. In the frontal lobe, normal aging had its largest effect in frontomesial cortex, whereas the ADrelated changes were mostly in fronto-lateral cortex. Similar effects of normal aging on CMRGlc had been described before (Kuhl et al., 1984; Petit-Taboue et al., 1998; Garraux et al., 1999), but had not yet been compared directly to AD-related changes. Among patients, late onset of disease was associated with less prominent local abnormalities, which is in accordance with previous studies (Mielke et al., 1992; Salmon et al., 2000), but had little consequence in the accuracy of discrimination between controls and patients above age 65 .

The present approach follows the concept of statistical parametric imaging (SPM) (Friston et al., 1995b), and actually uses the procedure provided by SPM99 for spatial normalization. Yet, it is the first study to apply this approach to a data set of several hundred subjects, which required new special program code (implemented using IDL) to handle the amount of data. In addition, we introduced $t$ sum and AD $t$ sum as new statistical indicators of global and AD-like scan abnormality. In contrast to comparisons of groups, which is the standard application of traditional statistical parametric mapping, these parameters provide a sensitive measure of individual scan abnormality which includes an adjustment for age-related changes (see Fig. 4 for an illustration). We validated them for future use as a clinical diagnostic instrument by using two separate subsets of normals, one for development of the indicators, and the other for testing them.

The AD $t$ sum was calculated from those regions that had shown a significant relation with dementia severity. To exclude potential overestimation of diagnostic accuracy due to the fact that those regions had been determined from the same sample, we also identified the regions with significant relation to dementia severity in a random subset of 103 patients with probable AD and performed the ROC analysis of diagnostic discrimination only in the remaining patients. The result was almost identical with sensitivity $94 \%$ and specificity $93 \%$.

We also solved the problem of different scanner resolution (Grady et al., 1989), which in the past has largely obviated data pooling and voxel-based multi-center PET studies. Of course, the effects of different scanner resolution could not be eliminated completely and were still recognizable as trends (see Table 3a), but in contrast to the huge significances that were obtained for the contrast between controls and AD, they were negligible. This was achieved by creation of a special mask that includes only the ridge of grey matter representation in the smoothed scans. Scanners with lower spatial resolution underestimate gray matter uptake due to contamination with surrounding low signal more than high-resolution scanners, and this effect is stronger in small structures than in larger ones (Maz-ziotta et al., 1981). Yet, with the additional heavy smoothing by a 12-mm Gaussian filter the effect becomes uniform enough in the gray matter ridge to result mainly in a globally lower signal which is then scaled to the same value in all subjects. As a result, we did not find significant resolutiondependent effects in normals and in the discrimination of patients from normals. There is certainly hope that with more widespread use of high-resolution scanners only one could even detect smaller abnormal volumes and thus improve diagnostic sensitivity, but that would also require further progress with spatial normalization which currently also requires smoothing to reduce residual signal variation caused by incomplete interindi-vidual gyrus matching after affine transformation. Analysis of high-resolution data and less smoothing probably would also be required to detect metabolic abnormalities of hippocampal structures (Jagust et al., 1993).

Partial volume effects due to cortical atrophy also lead to underestimation of local cerebral glucose metabolism (Meltzer et al., 1999). Although we did not correct explicitly for that, the effects of age-related atrophy were taken into account by adjustment of the normal reference values by linear regression on age. Local atrophy due 
to disease, in this case in particular due to $\mathrm{AD}$, does contribute to a reduction of the FDG PET signal in affected regions (Baron et al., 2001). Since we were not primarily interested in measuring accurate CMRGlc in this study, but to detect $\mathrm{AD}$, it was not necessary or even desirable to correct for an effect that is disease-related and possibly may improve diagnostic sensitivity. Previous studies (Alavi et al., 1993; Meltzer et al., 1996; Ibanez et al., 1998) demonstrated that, even after correction for atrophy, the reduction of CMRGlc persists in temporal and cingulate cortex and thus is not merely a consequence of atrophy. Thus, early cortical functional impairment that may precede atrophy is detected with high sensitivity by FDG PET, and in later stages atrophy may additionally contribute to signal loss because of partial volume effects.

The study opens the perspective to use this reference data base and the completely user-independent analysis of FDG PET in other diagnostic, longitudinal, and intervention studies of Alzheimer's disease and related conditions. Since the present study was based on clinical diagnosis as the gold standard, further studies are required to clarify the additional value of FDG PET with this automatic procedure over clinical assessment in predicting clinical decline and the histopathological diagnosis of AD in patients who present to the clinic with early dementia. The procedure is available for further scientific evaluation by submission of FDG PET resting brain images via FTP to the NEST-DD coordinator (see project homepage at www.nest-dd.org).

\section{ACKNOWLEDGMENT}

This study was conducted by the Network for Efficiency and Standardisation of Dementia Diagnosis (NESTDD) with support from the European Commission (Framework V). Work at CRC Lie'ge was also supported by grants from FNRS and FMRE, Belgium.

\section{REFERENCES}

Alavi, A., Newberg, A. B., Souder, E., and Berlin, J. A. 1993. Quantitative analysis of PET and MRI data in normal aging and Alzheimer's disease: Atrophy weighted total brain metabolism and absolute whole brain metabolism as reliable discriminators. J. Nucl. Med. 34: 16811687.

Baron, J. C, Chetelat, G., Desgranges, B., Perchey, G., Landeau, B., de 1, S. V., and Eustache, F. 2001. In vivo mapping of gray matter loss with voxel-based morphometry in mild alzheimer's disease. NeuroImage 14: 298-309.

Chu, C. C, Tranel, D., Damasio, A. R., and Van Hoesen, G. W. 1997. The autonomic-related cortex: Pathology in Alzheimer's disease. Cereb. Cortex7: 86-95.

de Leon, M. J., Convit, A., Wolf, O. T., Tarshish, C. Y., DeSanti, S., Rusinek, H., Tsui, W., Kandil, E., Scherer, A. J., Roche, A., Imossi, A., Thorn, E., Bobinski, M., Caraos, C, Lesbre, P., Schlyer, D., Poirier, J., Reisberg, B., and Fowler, J. 2001. Prediction of cognitive decline in normal elderly subjects with 2-F-18-fluoro-2-deoxy-D-glucose positron-emission tomography (FDG PET). Proc. Natl. Acad. Sci.USA98: 10966-10971.

Desgranges, B., Baron, J. C., de 1, S., Petit-Taboue, M. C., Benali, K., Landeau, B., Lechevalier, B., and Eustache, F. 1998. The neural substrates of memory systems impairment in Alzheimer's disease. A PET study of resting brain glucose utilization. Brain 121: 611-631.

Fama, R., Sullivan, E. V., Shear, P. K., Marsh, L., Yesavage, J. A., Tinklenberg, J. R., Lim, K. O., and Pfefferbaum, A. 1997. Selective cortical and hippocampal volume correlates of Mattis Dementia Rating Scale in Alzheimer disease. Arch. Neurol. 54: 719-728.

Folstein, M. F., Folstein, S. E., and McHugh, P. R. 1975. "Mini-mental state.” A practical method for grading the cognitive state of patients for the clinician. J. Psychiatr. Res. 12: 189-198.

Friston, K. J., Ashburner, J., Poline, J. B., Frith, C. D., Heather, J. D., and Frackowiak, R. S. J. 1995a. Spatial registration and normalisation of images. Human Brain Mapping 2: 165-189.

Friston, K. J., Holmes, A. P., Worsley, K. J., Poline, J. B., Frith, C. D., and Frackowiak, R. S. J. 1995b. Statistical parametric maps in functional imaging: a general linear approach. Human Brain Mapping 2: 189-210.

Garraux, G., Salmon, E., Degueldre, C, Lemaire, C, Laureys, S., and Franck, G. 1999. Comparison of impaired subcortico-frontal metabolic networks in normal aging, subcortico-frontal dementia, and cortical frontal dementia. NeuroImage 10: 149-162.

Grady, C. L., Berg, G., Carson, R. E., Daube-Witherspoon, M. E., Friedland, R. P., and Rapoport, S. I. 1989. Quantitative comparison of cerebral glucose metabolic rates from two positron emission tomographs. J. Nucl. Med. 30: 1386-1392.

Grigoletto, F., Zappala, G., Anderson, D. W., and Lebowitz, B. D. 1999. Norms for the Mini-Mental State Examination in a healthy population. Neurology 53: 315-320.

Grober, E., Buschke, H., Crystal, H., Bang, S., and Dresner, R. 1988. Screening for dementia by memory testing. Neurology 38: $900-903$.

Haxby, J. V., Duara, R., Grady, C. L., Cutler, N. R., and Rapoport, S. I. 1985. Relations between neuropsychological and cerebral metabolic asymmetries in early Alzheimer's disease. J. Cereb. Blood Flow Metab. 5: 193-200.

Haxby, J. V., Grady, C. L., Koss, E., Horwitz, B., Heston, L., Scha-piro, M., Friedland, R. P., and Rapoport, S. I. 1990. Longitudinal study of cerebral metabolic asymmetries and associated neuropsychological patterns in early dementia of the Alzheimer type. Arch. Neurol. 47: 753760 .

Henderson, V. W., and Buckwalter, J. G. 1994. Cognitive deficits of men and women with Alzheimer's disease. Neurology 44: 90-96. 
Herholz, K. 1995. FDG PET and differential diagnosis of dementia. Alzheimer Dis. Assoc. Disorders 9: 6-16.

Herholz, K., Adams, R., Kessler, J., Szelies, B., Grond, M., andHeiss, W. D. 1990. Criteria for the diagnosis of Alzheimer's disease with positron emission tomography. Dementia 1: 156-164.

Herholz, K., Nordberg, A., Salmon, E., Perani, D., Kessler, J., Mielke, R., Halber, M., Jelic, V., Almkvist, O., Collette, F., Alberoni, M., Kennedy, A., Hasselbalch, S., Fazio, F., and Heiss, W.-D. 1999. Impairment of neocortical metabolism predicts progression in Alzheimer's disease. Dementia Geriatr. Cog. Disord. 10: 494-504.

Herholz, K., Perani, D., Salmon, E., Franck, G., Fazio, F., Heiss, W. D., and Comar, D. 1993. Comparability of FDG PET studies in probable Alzheimer's disease. J. Nucl. Med. 34: 1460-1466.

Hoffman, J. M., Welsh-Bohmer, K. A., Hanson, M., Crain, B., Hu-lette, C, Earl, N., and Coleman, R. E. 2000. FDG PET imaging in patients with pathologically verified dementia. J. Nucl. Med. 41: 1920-1928.

Ibanez, V., Pietrini, P., Alexander, G. E., Furey, M. L., Teichberg, D., Rajapakse, J. C, Rapoport, S. I., Schapiro, M. B., and Horwitz, B. 1998. Regional glucose metabolic abnormalities are not the result of atrophy in Alzheimer's disease. Neurology 50: $1585-1593$.

Ichimiya, A., Herholz, K., Mielke, R., Kessler, J., Slansky, I., and Heiss, W. D. 1994. Difference of regional cerebral metabolic pattern between presenile and senile dementia of the Alzheimer type: A factor analytic study. J. Neurol. Sci. 123: 11-17.

Jagust, W. J., Eberling, J. L., Richardson, B. C, Reed, B. R., Baker, M. G., Nordahl, T. E., and Budinger, T. F. 1993. The cortical topography of temporal lobe hypometabolism in early Alzheimer's disease. Brain Res. 629: 189-198.

Kippenhan, J. S., Barker, W. W., Pascal, S., Nagel, J., and Duara, R. 1992. Evaluation of a neural-network classifier for PET scans of normal and Alzheimer's disease subjects. J. Nucl. Med. 33: 1459-1467.

Kuhl, D. E., Metter, E. J., Riege, W. H., and Hawkins, R. A. 1984. The effect of normal aging on patterns of local cerebral glucose utilization. Ann. Neurol. 15 (Suppl): S133-137.

Lim, A., Tsuang, D., Kukull, W., Nochlin, D., Leverenz, J., Mccormick, W., Bowen, J., Teri, L., Thompson, J., Peskind, E. R., Raskind, M., and Larson, E. B. 1999. Clinico-neuropathological correlation of Alzheimer's disease in a community-based case series. J Am. Geriatr. Soc. 47: $564-569$

Loewenstein, D. A., Barker, W. W., Chang, J. Y., Apicella, A., Yoshii, F., Kothari, P., Levin, B., and Duara, R. 1989. Predominant left hemisphere metabolic dysfunction in dementia. Arch. Neurol. 46: 146-152.

Mattis, S. 1988 Dementia Rating Scale (DRS). Psychological Assessment Resources, Inc., Odessa, FL.

Mazziotta, J. C, Phelps, M. E., Plummer, D., and Kuhl, D. E. 1981. Quantitation in positron emission computed tomography: 5. PhysicalAnatomical effects. J. Comput. Assist. Tomogr. 5: 734-743

Meltzer, C. C, Kinahan, P. E., Greer, P. J., Nichols, T. E., Comtat, C, Cantwell, M. N., Lin, M. P., and Price, J. C. 1999. Comparative evaluation of MR-based partial-volume correction schemes for PET. J. Nucl. Med. 40: 2053-2065.

Meltzer, C. C, Zubieta, J. K., Brandt, J., Tune, L. E., Mayberg, H. S., and Frost, J. J. 1996. Regional hypometabolism in Alzheimer's disease as measured by positron emission tomography after correction for effects of partial volume averaging. Neurology 47: 454-461.

Mendez, M. F., Mastri, A. R., Sung, J. H., and Frey, W. H. 1992. Clinically diagnosed Alzheimer disease: Neuropathologic findings in 650 cases. Alzheimer Dis. Assoc. Disord. 6: $35-43$.

Messa, C, Perani, D., Lucignani, G., Zenorini, A., Zito, F., Rizzo, G., Grassi, F., Del Sole, A., Franceschi, M., Gilardi, M. C, et al. 1994. High-resolution technetium-99m-HMPAO SPECT in patients with probable Alzheimer's disease: Comparison with fluorine-18-FDG PET. $J$. Nucl. Med. 35: 210-216.

Metz, C. E. 1978. Basic principles of ROC analysis. Semin. Nuclear Med. 8: 283-298.

Mielke, R., Herholz, K., Grond, M., Kessler, J., and Heiss, W. D. 1992. Differences of regional cerebral glucose metabolism between presenile and senile dementia of Alzheimer type. Neurobiol. Aging 13: 93-98.

Mielke, R., Pietrzyk, U., Jacobs, A., Fink, G. R., Ichimiya, A., Kessler, J., Herholz, K., and Heiss, W. D. 1994. HMPAO SPET and FDG PET in Alzheimer's disease and vascular dementia: comparison of perfusion and metabolic pattern. Eur. J. Nucl. Med. 21: 1052-1060.

Minoshima, S., Frey, K. A., Koeppe, R. A., Foster, N. L., and Kuhl, D. E. 1995. A diagnostic approach in Alzheimer's disease using threedimensional stereotactic surface projections of fluorine-18-FDG PET. J. Nucl. Med. 36: 1238-1248.

Morris, J. C. 1993. The Clinical Dementia Rating (CDR): Current version and scoring rules [see comments]. Neurology 43: $2412-2414$.

Morris, J. C, McKeel, D. W., Jr., Fulling, K., Torack, R. M., and Berg, L. 1988. Validation of clinical diagnostic criteria for Alzheimer's disease. Ann. Neurol. 24: 17-22.

Mungas, D., Marshall, S. C, Weldon, M., Haan, M., and Reed, B. R. 1996. Age and education correction of Mini-Mental State Examination for English and Spanish-speaking elderly. Neurology 46: 700-706.

Perani, D., and Cappa, S. F. 2001. Brain imaging in normal aging and dementia. In Normal Aging and Dementia. Handbook of Neuropsychology (J. Grafman and F. Boller, Eds.). Elsevier, Amsterdam.

Petit-Taboue, M. C, Landeau, B., Desson, J. F., Desgranges, B., and Baron, J. C. 1998. Effects of healthy aging on the regional cerebral metabolic rate of glucose assessed with statistical parametric mapping. NeuroImage 7: 176-184.

Pietrzyk, U., Herholz, K., Schuster, A., von Stockhausen, H. M., Lucht, H., and Heiss, W. D. 1996. Clinical applications of registration and fusion of multimodality brain images from PET, SPECT, CT, and MRI. Eur. J. Radiol. 21: 174-182.

Rapoport, S. I. 1991. Positron emission tomography in Alzheimer's disease in relation to disease pathogenesis-A critical review. Cerebrovasc. Brain Metab. Rev. 3: 297-335. 
Rapoport, S. I. 1997. Discriminant analysis of brain imaging data identifies subjects with early Alzheimer's disease. Int. Psychogeri-atr. 9 (Suppl. 1): 229-235.

Reiman, E. M., Caselli, R. J., Yun, L. S., Chen, K., Bandy, D., Minoshima, S., Thibodeau, S. N., and Osborne, D. 1996. Preclinical evidence of Alzheimer's disease in persons homozygous for the epsilon 4 allele for apolipoprotein E. N. Engl. J. Med. 334: $752-758$.

Reisberg, B., Ferris, S. H., DeLeon, M. J., and Crook, T. 1982. The global deterioration scale for assessment of primary degenerative dementia. Am. J. Psych. 139: 1136-1139.

Salmon, E., Collette, F., Degueldre, C, Lemaire, C, and Franck, G. 2000. Voxel-based analysis of confounding effects of age and dementia severity on cerebral metabolism in Alzheimer's disease. Human Brain Mapping 10: 39-48.

Salmon, E., Sadzot, B., Maquet, P., Degueldre, C, Lemaire, C, Rigo, P., Comar, D., and Franck, G. 1994. Differential diagnosis of Alzheimer's disease with PET. J. Nucl. Med. 35: 391-398.

Signorini, M., Paulesu, E., Friston, K., Perani, D., Colleluori, A., Lucignani, G., Grassi, F., Bettinardi, V., Frackowiak, R. S. J., and Fazio, F. 1999. Rapid assessment of regional cerebral metabolic abnormalities in single subjects with quantitative and nonquantitative [18F]FDG PET: A clinical validation of statistical parametric mapping. NeuroImage 9: 63-80.

Silverman, D. H., Small, G. W., Chang, C. Y., Lu, C. S., Kung de Aburto, M. A., Chen, W., Czemin, J., Rapoport, S. I., Pietrini, P., Alexander, G. E., Schapiro, M. B., Jagust, W. J., Hoffman, J. M., Welsh-Bohmer, K. A., Alavi, A., Clark, C. M., Salmon, E., de Leon, M. J., Mielke, R., Cummings, J. L., Kowell, A. P., Gambhir, S. S., Hoh, C. K., and Phelps, M. E. 2001. Positron emission tomography in evaluation of dementia: Regional brain metabolism and long-term outcome. JAMA 286: 2120-2127.

Small, G. W., Ercoli, L. M., Silverman, D. H., Huang, S. C., Komo, S., Bookheimer, S. Y., Lavretsky, H., Miller, K., Siddarth, P., Rasgon, N. L., Mazziotta, J. C., Saxena, S., Wu, H. M., Mega, M. S., Cummings, J. L., Saunders, A. M., Pericak-Vance, M. A., Roses, A. D., Barrio, J. R., and Phelps, M. E. 2000. Cerebral metabolic and cognitive decline in persons at genetic risk for Alzheimer's disease. Proc. Natl. Acad. Sci. USA 97: 6037-6042.

Steel, R. D. G., and Torrie, J. H. 1980 Principles and Procedures of Statistics. A Biometrical Approach. McGraw-Hill, New York.

Thompson, P. M., Moussai, J., Zohoori, S., Goldkorn, A., Khan, A. A., Mega, M. S., Small, G. W., Cummings, J. L., and Toga, A. W. 1998. Cortical variability and asymmetry in normal aging and Alzheimer's disease. Cereb. Cortex 8: 492-509.

Thompson, P. M., Schwartz, C., Lin, R. T., Khan, A. A., and Toga, A. W. 1996. Three-dimensional statistical analysis of sulcal variability in the human brain. J. Neurosci. 16: 4261-4274.

Wechsler, D. 1987. Wechsler Memory Scale-Revised. Psychological Corp., New York. 